\title{
Self-Concept Clarity Across Adolescence: Longitudinal Associations With Open Communication With Parents and Internalizing Symptoms
}

\author{
Marloes P. A. Van Dijk • Susan Branje • \\ Loes Keijsers · Skyler T. Hawk • William W. Hale III • \\ Wim Meeus
}

Received: 11 June 2013/Accepted: 4 November 2013/Published online: 23 November 2013

(C) Springer Science+Business Media New York 2013

\begin{abstract}
Higher self-concept clarity is related to several adjustment indices and may be promoted by open communication with parents, while problems with self-concept clarity development could enhance internalizing problems (i.e., depressive and anxiety symptoms) in adolescence. This longitudinal study examined linkages between selfconcept clarity, adolescents' open communication with parents, and adolescent depressive and anxiety symptoms. Dutch youths $(N=323 ; 51.1 \%$ girls; mean age Time $1=13.3$ years) reported on these constructs over four consecutive annual measurements. Concurrent positive links between open communication and self-concept clarity were found at Time 1. Over time, higher levels of open communication with parents predicted higher self-concept clarity only in middle adolescence (mean age between 14
\end{abstract}

M. P. A. Van Dijk $(\bowtie) \cdot$ S. Branje $\cdot$ L. Keijsers ·

S. T. Hawk - W. W. Hale III - W. Meeus

Research Centre Adolescent Development, Utrecht University, P.O. Box 80140, 3508 TC Utrecht, The Netherlands

e-mail: M.P.A.vanDijk@uu.nl

S. Branje

e-mail: s.branje@uu.nl

L. Keijsers

e-mail: L.Keijsers@uu.nl

S. T. Hawk

e-mail: S.T.Hawk@uu.nl

W. W. Hale III

e-mail: b.hale@uu.nl

W. Meeus

e-mail:w.meeus@uu.nl

W. Meeus

Developmental Psychology, School of Social and Behavioral Sciences, Tilburg University, P.O. Box 90153, 5000 LE Tilburg,

The Netherlands and 15 years). We also found concurrent associations between self-concept clarity and both depressive and anxiety symptoms. Longitudinally, lower self-concept clarity predicted relatively higher levels of depressive symptoms across all waves, and also higher anxiety levels from Time 1 to Time 2. Conversely, higher levels of anxiety also predicted lower levels of self-concept clarity during the first three waves. Self-concept clarity did not mediate the longitudinal associations between open communication and internalizing symptoms. This study is one of the first to investigate self-concept clarity across adolescence. It highlights the possible importance of both anxiety symptoms and communication with parents in understanding the development of a clear self-concept, and demonstrates an association between lower self-concept clarity and higher levels of later depressive and anxiety symptoms.

Keywords Adolescence - Self-concept clarity · Open communication $\cdot$ Internalizing problems

\section{Introduction}

"Don't laugh at a youth for his affectations; he is only trying on one face after another to find a face of his own" (Pearsall Smith 1931). Indeed, an important task in adolescence is the development of the self and identity (Erikson 1963; Marcia 1966; Meeus et al. 2010), and an essential aspect of the self is self-concept clarity (Bigler et al. 2001; Campbell et al. 1996; Schwartz et al. 2010). Self-concept clarity is the extent to which beliefs about the self are clearly and confidently defined, stable over time, and internally consistent (Campbell et al. 1996). In other words, self-concept clarity refers to the structure of the self-concept, regardless of the content. Central to the 
development of the self is a process of self-reflective thinking and talking, in order to enhance understanding of the self (Habermas and Bluck 2000). Besides this process, which presumably also occurs within parent-adolescent interactions, open communication with parents might help adolescents to promote individuation within the context of a warm relationship (Arnett 1999). Therefore, developing the self may be established partly within parent-child interactions, especially when parents are active listeners and supportive of the adolescent's viewpoints (Grotevant and Cooper 1985; Grotevant 2001; McLean et al. 2007; Shaw 1997). In addition, for some youths, adolescence is characterized by an increase in emotional difficulties (Arnett 1999). When developing and structuring their selfconcepts, adolescents' increased frequency of thinking about oneself might enhance internalizing problems, such as depression and anxiety, as youths start to consider their whole lives (Habermas and Bluck 2000). Therefore, we examined the associations between open communication with parents, self-concept clarity, and internalizing problems across adolescence, using a longitudinal design.

Self-concept clarity gauges the stability of the self-concept, as it comprises how consistently an individual perceives him or herself (Campbell 1990). Self-concept clarity refers to the structure of the self-concept, as opposed to the content of the self-concept. The clarity of the self is positively related to several adjustment indices, such as selfesteem (Campbell et al. 1996; Donahue et al. 1993) and commitment-making (Schwartz et al. 2010). The structural aspects of one's self-concept are thought to have unique predictive value for emotional adjustment apart from the influence of the content aspects (the knowledge and evaluative components of the self-concept; Campbell et al. 1996), such as self-esteem. For example, although self-concept clarity is positively related to self-esteem (Campbell et al. 1996; Donahue et al. 1993), most individuals with lower self-esteem do not have a negative self-concept (Campbell 1990). Instead, they have a self-concept that is "neutral", meaning the self-concept is relatively uncertain, unstable, and internally inconsistent (i.e., low clarity) (Campbell 1990). People with lower self-concept clarity are more dependent on and more susceptible to the influence of external factors (Campbell 1990). In contrast, individuals with higher self-concept clarity are less affected by (negative) external cues that are not consistent with their selfconcept. They are also more flexible in responding to the social environment (Campbell 1990). Furthermore, selfconcept clarity is strongly tied to healthy identity development (Campbell et al. 1996; Schwartz et al. 2010). For instance, among adolescents, relative changes in self-concept clarity and commitment-making are reciprocally and positively associated (Schwartz et al. 2010). Identity can be seen as providing the structure for understanding who one is
(Adams and Marshall 1996). Thus, gaining higher selfconcept clarity seems to be an essential part of healthy development during adolescence.

\section{Links Between Open Communication and Self-Concept Clarity}

Theoretically, a process of self-reflective thinking and narrative construction should promote development of the self and identity (Habermas and Bluck 2000). This thinking and talking enhances understanding by actively creating associations between events and the self. Development of the self consists of these narratives becoming increasing coherent and elaborate. "Sharing stories is the mechanism through which people become selves" (McLean et al. 2007, p. 275), and parts of the self-concept are made up of interactions with others and the expectations they communicate (Grotevant 2001; Shaw 1997). In adolescence, participating in family interactions that allow for open expression of ideas and opinions may help to foster clarity in the adolescent's developing sense of self (Grotevant and Cooper 1985). Family interactions in which family members show acceptance towards the adolescent's views and ideas can give the adolescent the confidence and skills necessary to explore away from the family. Furthermore, talking with parents promotes adolescents' development and understanding of the self (McLean et al. 2007), particularly when there is a generally high level of open communication. As such, communication with parents who provide evaluative comments, engage in active listening, and are more supportive of the adolescent's view in the conversation can be more helpful in the development of the self, compared to parent-adolescent communication that is less open (McLean et al. 2007).

Although communication between parents and adolescents may become increasingly challenged as adolescents attempt to become autonomous (Finkenauer et al. 2002), open communication may promote the development of individuation and autonomy within the context of a warm relationship (Arnett 1999). That is, in optimal development, adolescents integrate their need to construct a separate self and their need for warm relationships with parents (Adams and Marshall 1996; Grotevant and Cooper 1985; Hill and Holmbeck 1986). Open communication with peers or friends might also be relevant to the development of higher self-concept clarity, because the influence of friends increases during adolescence (De Goede et al. 2009). Still, youths' relationships with their parents continue to be predictive of well-being into late adolescence (Hair et al. 2008).

A limited amount of empirical research supports the idea of an association between open communication and selfconcept clarity. For instance, one cross-sectional study 
showed that open communication with parents is related to adolescents' identity exploration (Meeus et al. 2002). In a rare longitudinal study over different age groups, adolescents who had less open communication with their parents (i.e., kept more secrets) experienced lower self-concept clarity 6 months later, but no link was found from selfconcept clarity to later communication with parents (Frijns and Finkenauer 2009). The effect of communication with parents could be larger in early adolescence than in later adolescence, however, due to the diminishing influence of parents (De Goede et al. 2009; Meeus et al. 2005).

Although these findings indicate that open communication with parents is concurrently linked to self-concept clarity, and that communication with parents precedes selfconcept clarity, self-concept clarity may also precede communication with parents. This is because, generally speaking, children's adjustment has been shown to predict adolescents' subsequent perceived relationship quality with parents (Bell 1968; Branje et al. 2010; Kerr and Stattin 2003; Van Eijck et al. 2012). Furthermore, the self has an influence on our close relationships, because understanding of oneself influences individuals' reactions and levels of disclosure to others (Aron 2003). Although we had more evidence (and therefore stronger expectations) for higher open communication with parents as a predictor of later higher self-concept clarity than for the reverse direction, we tested for bidirectional associations between open communication and self-concept clarity.

Hence, an extended longitudinal study is needed to examine the over-time associations of these variables across adolescence, and to investigate long-term implications for adolescents of different ages. Accordingly, the first research question was: Are higher levels of open communication with parents concurrently and bidirectionally associated with higher self-concept clarity and, if so, at what ages?

\section{Links Between Self-Concept Clarity and Internalizing Problems}

During adolescence, the increased frequency of thinking about oneself may enhance internalizing problems for some youths, as they start to think about their lives as a whole (Habermas and Bluck 2000). As adolescents' selfconcepts develop, they might ruminate (an involuntary, emotionally negative form of self-focus associated with threat or uncertainty; Campbell et al. 1996), which is a strong predictor of internalizing problems such as depression and social anxiety (Panayiotou and Kokkinos 2006). In addition, it is plausible that adolescents' uncertainty about their self-concepts contributes to depressive and anxious feelings (Campbell et al. 2003). In adolescence, periods of heightened self-reflection (i.e., thinking and talking about the self and one's life) can go together with temporary declines in self-esteem and other adjustment indices because youths are struggling with problematic issues in their lives (Bell et al. 2004). Thus, we expected within-time associations between lower self-concept clarity and higher levels of anxiety and depressive symptoms, and also that lower self-concept clarity may precede higher levels of internalizing problems. Additionally, higher anxiety levels may also precede lower self-concept clarity. Although there is less theoretical attention to this direction of associations over time, high anxiety has been identified as a risk factor for identity development (Crocetti et al. 2009), because anxiety relates to more uncertainty. Similar linkages could be expected for adolescents with more depressive symptoms. On the other hand, anxiety and depressive symptoms appear to co-occur with reconsideration, which in some cases leads to adopting subsequent commitments and an increase in self-concept clarity (Meeus et al. 2010; Schwartz et al. 2012). Therefore, we had no clear hypothesis regarding the valence of the relationship between internalizing problems and later selfconcept clarity.

Empirical evidence offers support for a negative crosssectional association between self-concept clarity and internalizing problems. Lower self-concept clarity has been linked to higher depression and anxiety in both college students and inpatient psychiatric samples (Bigler et al. 2001). Additional studies have shown lower self-concept clarity also to be associated with higher neuroticism and lower self-esteem (Campbell et al. 1996; Donahue et al. 1993). Moreover, a prior longitudinal study on adults provides evidence for an association between self-concept clarity and internalizing problems, in which higher selfconcept clarity was related to lower average levels of negative affect over a 7-day period (Lee-Flynn et al. 2011). In this research, higher levels of self-concept clarity also predicted lower levels of depressive symptoms 2 years later (Lee-Flynn et al. 2011). Relatedly, one study among young adolescents showed that confusion regarding identity processes served as a precursor to anxiety and depression, but not vice versa (Schwartz et al. 2010). Regarding the over-time associations of internalizing problems and later self-concept clarity, a study among college students found that, over time, negative affect mediated the association between negative daily events and daily self-concept clarity (Nezlek and Plesko 2001). These findings suggest that increases in negative affect precede decreases in self-concept clarity.

To our knowledge, only one other study has previously examined longitudinal associations between self-concept clarity and internalizing problems in adolescence (Schwartz et al. 2012). Using partly the same sample as the current study, including a larger and more ethnically diverse group 
of adolescents who less often came from two-parent families than the current sample, this investigation found bidirectional associations between self-concept clarity and both depressive and anxiety symptoms over time. Furthermore, self-concept clarity was a stronger predictor of anxiety and depressive symptoms than vice versa. In contrast to the study of Schwartz et al. (2012), however, the current study examined age differences in these long-term associations. In addition to more individual factors (self-concept clarity and internalizing symptoms), we also included a family process factor, open communication, that was only available for a smaller subsample of participants. In this way, we were able to examine how these intra-individual processes of selfrelated cognitions and mood are linked to interpersonal communication processes. Since we wanted to examine the over-time associations of self-concept clarity and internalizing problems across adolescence in more detail, the second research question was: Is lower self-concept clarity concurrently and bidirectionally related to a higher level of internalizing problems and, if so, at what ages? We treated depressive and anxiety symptoms separately. Although previous findings often concerned both depressive and anxiety symptoms, they are also found to have different relationships with other constructs (e.g., self-esteem, Sowislo and Orth 2013).

\section{Does Self-Concept Clarity Mediate the Association Between Open Communication and Internalizing Problems?}

A major innovation of the present investigation concerns an attempt to link the prior research on open adolescentparent communication and self-concept clarity with earlier studies on self-concept clarity and internalizing symptoms. Several cross-sectional and longitudinal studies have reported an association between adolescents' unwillingness to communicate with their parents and aspects of psychosocial well-being, such as depressive symptoms (e.g., Frijns and Finkenauer 2009; Frijns et al. 2010; Jackson et al. 1998; Kerr and Stattin 2000), but the mechanisms through which lack of open communication precedes these problems remain unclear. Self-concept clarity might be a crucial mediating factor in this association, as higher open communication with parents seems to increase self-concept clarity, which in turn likely precedes higher psychological well-being. A cross-sectional study among university students found a mediation effect of identity gaps in the relation between communication and depression (Jung 2013). This showed how closely these three areas seem to be related to each other, and suggests that the development of the self could be a mechanism that links communication to internalizing problems. The present study will investigate this possibility using a longitudinal design. Thus, the third research question was: Does self-concept clarity mediate the negative links between open communication with parents and internalizing problems (depressive and anxiety symptoms)?

\section{The Present Study}

The present study examined links over time between adolescents' communication with parents, self-concept clarity, and internalizing problems. By investigating not only selfconcept clarity and internalizing problems, but also open communication, this research focused on important individual and family processes that have heretofore not been examined in a single study. Firstly, we investigated the within- and over-time associations between self-concept clarity and open communication with parents. We expected that higher open communication with parents would be concurrently and longitudinally related to higher self-concept clarity. Secondly, we examined the within- and overtime associations between self-concept clarity and internalizing problems. We hypothesized that higher self-concept clarity would be concurrently related, and show bidirectional links over time, with lower levels of internalizing problems. Finally, we examined self-concept clarity as a potential mediator in the longitudinal association between open communication with parents and internalizing problems. We hypothesized that higher open communication with parents would predict higher selfconcept clarity, which in turn would predict less internalizing problems.

\section{Methods}

\section{Participants}

Data for this study came from a subsample of 323 adolescents participating in an ongoing longitudinal study on relationships and conflicts in adolescence, named CONAMORE (conflicts and management of relationships; Meeus et al. 2006). Adolescents were recruited from various randomly selected high schools located in the province of Utrecht, The Netherlands. Of the original 923 adolescents, families of 656 Dutch early adolescents were invited to participate in additional annual home-visits. Of those who were invited, 491 families accepted the invitation, and 401 of them were two-parent families. The current sample of 323 (51.1\% female; $98.7 \%$ Dutch) was randomly selected because of the limited financial budget. We used this subsample because only in this sample did we assess open communication with parents. At the start of the study, $99.1 \%$ of adolescents were in the second year of junior 
high, ages ranged from 12 to 15 years $(\mathrm{M}=13.3$, $\mathrm{SD}=0.5$ ), and $97.8 \%$ of the adolescents lived with both parents $(1.2 \%$ with their mother or mother and stepfather, $0.6 \%$ with their father or father and stepmother, and $0.3 \%$ had another living situation). This sample was relatively highly educated, with approximately $50 \%$ at schools preparing for university, $35 \%$ of the adolescents preparing for higher education, and $15 \%$ of the adolescents preparing for blue-collar work. We used data from four measurement waves that were spaced 1 year apart.

\section{Procedure}

Before actual data collection started (2002), adolescents and their parents were informed about the aims of the study and they provided written informed consent. Adolescents annually filled out a battery of questionnaires at school, but after school hours. In addition, there were annual homevisits in which both parents also participated. Trained research assistants provided verbal instructions, in addition to the written instructions that accompanied the questionnaires. As a reward, families received the equivalent of US \$35 (€27) per home-visit and adolescents received an additional amount per assessment at school, the equivalent of US \$13 (€10). Confidentiality of responses was assured. This study was approved by the board of the local research institute. For more information regarding the selection of the sample and the procedure, see Van Doorn et al. (2007).

\section{Measures}

\section{Self-Concept Clarity}

The extent to which participants' self-beliefs were clearly and confidently defined, internally consistent, and stable (i.e., self-concept clarity), was measured using the 12-item Self-Concept Clarity Scale (Campbell et al. 1996). Answers were given on a Likert scale with answer possibilities ranging from 1 (strongly disagree) to 5 (strongly agree). Item examples are: "Even if I wanted to, I don't think I could tell someone what I'm really like" or "My beliefs about myself often conflict with one another". Mean scale scores were computed so that higher scores indicate higher self-concept clarity. Reliability as well as construct and criterion validity of the scale are supported (Campbell et al. 1996). In the current sample, internal consistency was good (Cronbach's $\alpha$ varied from .86 to .89 at the different waves).

\section{Depressive Symptoms}

Adolescent symptoms of depression were measured using a 27-item self-report scale for 8- to 17-year olds, the children's depression inventory (CDI; Craighead et al. 1998). Items were scored on a three-point Likert type scale with possible answers ranging from 1 (false) to 3 (very true). Item examples are: "I am sad all the time", and "I will never end up all right". The mean score on this scale was used within the analyses. Cronbach's $\alpha$ ranged from .87 to .89 across the waves.

\section{Anxiety Symptoms}

The Screen for Child Anxiety Related Emotional Disorders (SCARED; Birmaher et al. 1997) was used to measure anxiety symptoms, which is appropriate for children and adolescents from age 7 to 19 years. The scale consists of 38 three-point Likert scale items, which measure five different kinds of anxiety (i.e., generalized anxiety, panic, school anxiety, separation anxiety, and social phobia). Answers indicate occurrence of anxiety symptoms and are ranging from 0 (almost never) to 2 (often). Item examples are "I worry too much" and "I feel nervous with people I don't know well". In the present study, the mean of the total anxiety scale was used as indicator of anxiety. The SCARED is shown to be a valid and reliable instrument (Birmaher et al. 1999), also in Dutch samples (Hale et al. 2011). In the current sample, Cronbach's $\alpha$ was .96 across the measurement points.

\section{Open Communication}

Openness in parent-adolescent communication was measured with the Open Communication Scale (Jackson et al. 1998), a Dutch translation of the Parent-adolescent Communication Scale (Barnes and Olson 1985). The scale contains 10 five-point Likert scale items, with response categories ranging from 1 (no, certainly not) to 5 (yes, certainly). Item examples are "It is easy for me to express all my true feelings to my parents" and "My parents are always good listeners". Mean scores were used within the analyses. Findings regarding the psychometric qualities of the scale are satisfactory (Jackson et al. 1998). Internal consistency within the current sample was good or excellent, with Cronbach's $\alpha$ ranging from .85 to .90 in the different waves.

\section{Strategy of Analyses}

Models were estimated with Mplus v7.1 (Muthén and Muthén 1998-2012). For each variable, a maximum of $4.3 \%$ of cases was missing. Little's (1988) missing completely at random (MCAR) test was performed to estimate the pattern of missing values. Although this very stringent test was significant $\left[\chi^{2}(N=323, d f=187)=372.97\right.$, $p<.001]$, the $\chi^{2} / d f$ ratio of 1.99 indicated a good fit 
between scores in the sample that were imputed and the scores that were non-missing (Bollen 1989). No consistent relationships were found between missingness on variables and other variables, or the same variables at other waves. This indicates that data were likely missing at random. Because of this pattern and because so very few cases were missing, we could use Full Information Maximum Likelihood (FIML: Enders and Bandalos 2001) with robust estimates (MLR: Satorra and Bentler 1994), because of the skewed variables (e.g., depressive symptoms). This method performs adequately for data that are completely missing at random as well as for data that are missing at random (Widaman 2006). Model fit was evaluated by the comparative fit index (CFI) and the root mean square of error of approximation (RMSEA), with respective values above .95 and up to .08 indicating an acceptable fit of the model (Hu and Bentler 1999). Adjusted Chi square difference tests (Satorra and Bentler 2001) were performed to compare the different models.

To test our hypotheses, we used two series of crosslagged path analyses including open communication, selfconcept clarity, and either depressive symptoms or anxiety symptoms. The baseline model included 1-, 2-, and 3-year stabilities, concurrent correlations, and correlated errors within time for open communication, self-concept clarity, and depressive or anxiety symptoms, respectively. No cross-lagged effects between the variables were included in this baseline model. The over-time associations between open communication, self-concept clarity, and internalizing problems were tested by examining whether adding cross-lagged paths to the baseline model resulted in a better fit to the data (Kline 2011). The cross-lagged paths for which we had most evidence were added to the baseline model first, in the sequence over time we hypothesized (Fig. 1; cf. Burt and Roisman 2010). This means that in Model 1, the cross-lagged paths from open communication with parents to self-concept clarity were added to the baseline model (i.e., Model 0), and in Model 2, the crosslagged paths from self-concept clarity to depressive or anxiety symptoms were added to Model 1 . In Models 3 and 4 , the cross-lagged paths for which we had less evidence (but a theoretical rational) were added (Fig. 1). Thus, in Model 3 the cross-lagged paths of depressive or anxiety symptoms to self-concept clarity were added to Model 2, and in Model 4 the paths of self-concept clarity to open communication were added to Model 3. To be more secure about our findings, we also tested adding the paths in the reverse direction. Although we examined two final models including open communication, self-concept clarity, and either depressive or anxiety symptoms, the results are described separately for open communication and selfconcept clarity and for self-concept clarity and the two types of internalizing problems.

\section{Results}

Descriptive Statistics and Intercorrelations

Mean levels, standard deviations, and intercorrelations of open communication, self-concept clarity, anxiety symptoms, and depressive symptoms for each wave are presented in Table 1. Open communication, self-concept clarity, depressive symptom scores, and anxiety symptom scores were moderately stable over time. Mean scores on self-concept clarity showed positive, medium-sized correlations (Cohen 1988) with mean scores on open communication with parents. Higher mean scores on self-concept clarity were related to lower scores on depressive symptoms (large effect sizes) and anxiety symptoms (medium to large effect sizes). Correlations between open communication and anxiety and depressive symptoms were negative and small-to-medium-sized. Finally, depressive and anxiety symptoms were positively correlated, with large effect sizes.

Over-Time Associations Between Open

Communication and Self-Concept Clarity

As part of the aforementioned sequence of adding crosslagged paths to the baseline model (Fig. 1), we tested whether adding cross-lagged effects between self-concept clarity and open communication would improve fit of the models including depressive or anxiety symptoms, respectively. As was indicated by a significant $\chi^{2}$ difference test (see Table 2), adding hypothesized cross-lagged paths from open communication to self-concept clarity significantly improved the fit to the data, compared to the baseline model with only stabilities, within-wave Time 1 (T1) correlations and correlated residuals. Adding the reverse cross-lagged paths did not result in a better model fit (see Table 2). Therefore, only cross-lagged paths from open communication to self-concept clarity were added to the baseline models. The reverse order of model testing yielded the same results. A significant, medium-sized correlation between open communication and self-concept clarity was present at Time 1 . The within-wave correlated residuals were consistent and small-sized, indicating that self-concept clarity and open communication are linked. Effects of open communication on later self-concept clarity were only significant from Time 2 to Time $3, \beta=.19$, $p<.01$ in the model including depressive symptoms, and $\beta=.21, p<.01$ in the model including anxiety symptoms. Model fit was good for the final model including open communication, self-concept clarity, and depressive symptoms $\left[\chi^{2}(30)=30.02, p=.465 ; \mathrm{CFI}=1.000\right.$; RMSEA $=$ .001 (90\% CI .000-.042)] and also for the model including open communication, self-concept clarity, and anxiety 


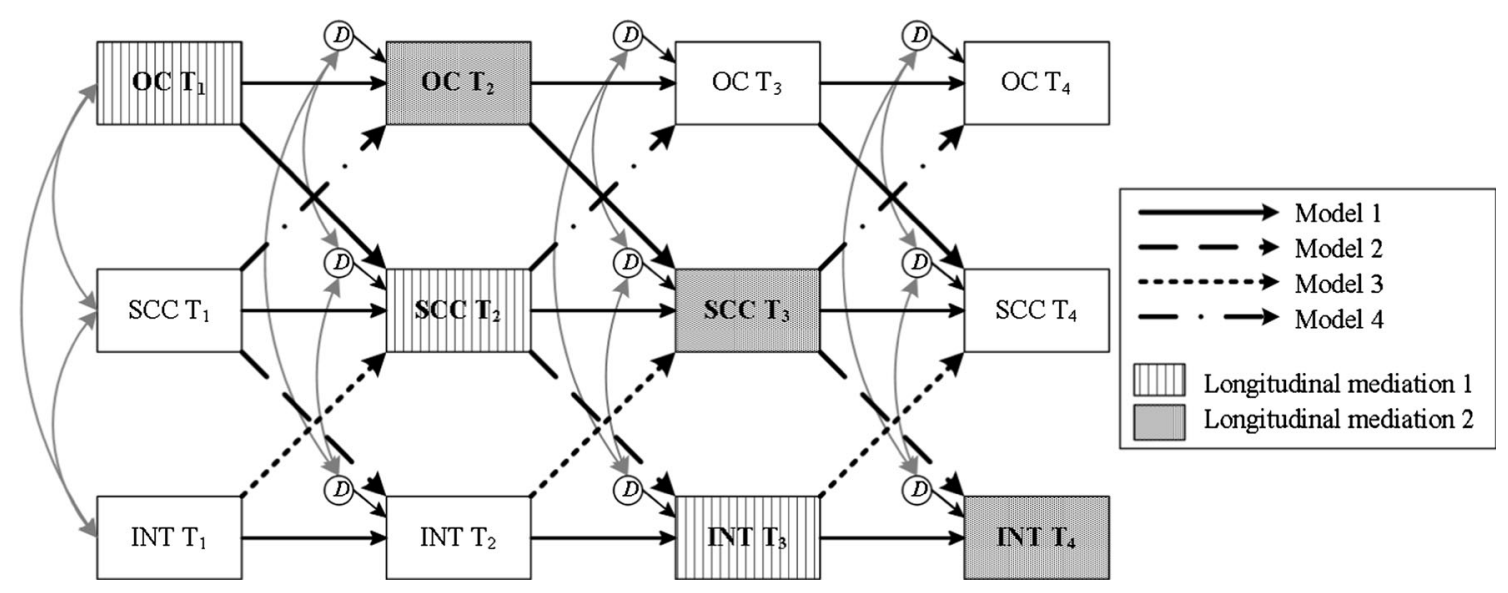

Fig. 1 Tested cross-lagged panel meditation model with self-concept clarity as hypothesized mediator in the relationship between open communication with parents and internalizing problems over time. $O C$ open communication with parents, $S C C$ self-concept clarity, INT

symptoms $\quad\left[\chi^{2}(27)=22.67, \quad p=.703 ; \quad\right.$ CFI $=1.000$; RMSEA $<.001(90 \%$ CI .000-.034)]. No gender differences were found for the $\mathrm{T} 1$ correlations and for the crosslagged paths (model including depressive symptoms: $\Delta \chi^{2}=11.18, \Delta d f=9, p=.26$; model including anxiety symptoms: $\Delta \chi^{2}=5.67, \Delta d f=12, p=.95$ ). Results are presented in (Figs. 2 and 3, and in Table 3.

\section{Over-Time Associations Between Self-Concept Clarity and Internalizing Symptoms}

Within the described order of adding cross-lagged paths (Fig. 1), we tested whether adding cross-lagged paths to the baseline model between self-concept clarity and internalizing problems would improve model fit. For the model on depressive symptoms, only the cross-lagged paths from self-concept clarity to depressive symptoms significantly improved the model fit (see Table 2). Hence, these paths were included. At Time 1, there was a large-sized correlation between self-concept clarity and depressive symptoms, and there were medium-sized correlated residuals within measurement waves. Over time, moreover, lower self-concept clarity significantly predicted higher levels of depressive symptoms, with $\beta$ s ranging from -.15 to -.19 (see Fig. 2; Table 3). The final model contained crosslagged paths from open communication to self-concept clarity and from self-concept clarity to depressive symptoms, and had a good model fit $\left[\chi^{2}(30)=30.02, p=.465\right.$; $\mathrm{CFI}=1.000 ;$ RMSEA $=.001(90 \%$ CI .000-.042) $]$.

For anxiety symptoms, model fit improved when adding cross-lagged paths from self-concept clarity to anxiety symptoms and from anxiety symptoms to self-concept clarity, as shown by $\chi^{2}$ difference tests for the different internalizing problems. 'Internalizing problems' stands for respectively depressive symptoms and anxiety symptoms in the two separate analyses. Hypothesized longitudinal mediation effects were modeled in the final cross-lagged path models

models (Fig. 1; Table 2). At Time 1, the correlation between self-concept clarity and anxiety symptoms was large and significant. Within the waves, the correlated residuals were consistent and small-to-medium-sized. The path from anxiety symptoms to self-concept clarity was only significant from Time 1 to Time $2, \beta=-.12, p<.05$, and from Time 2 to Time $3, \beta=-.16, p<.01$. The cross-lagged effect of self-concept clarity to anxiety symptoms was only significant from Time 1 to Time $2, \beta=-.21, p<.01$ (see Fig. 3; Table 3). Model fit was good for the final model including cross-lagged paths from open communication to self-concept clarity, from self-concept clarity to anxiety symptoms, and from anxiety symptoms to self-concept clarity: $\chi^{2}(27)=22.67, p=.703$; CFI $=1.000$; RMSEA $<.001$ (90\% CI .000-.034). The reverse order of adding cross-lagged paths yielded the same conclusions for the models including depressive and anxiety symptoms, respectively. Furthermore, no gender differences were found for the $\mathrm{T} 1$ correlations and for the cross-lagged paths (model including depressive symptoms: $\Delta \chi^{2}=11.18$, $\Delta d f=9, p=.26$; model including anxiety symptoms: $\left.\Delta \chi^{2}=5.67, \Delta d f=12, p=.95\right)$.

Self-Concept Clarity a Mediator in the Link Between Open Communication and Internalizing Problems

To test whether self-concept clarity mediated the links between open communication and internalizing problems, two longitudinal indirect effects were tested within the two final cross-lagged path models (with depressive or anxiety symptoms, respectively, as outcome measures; see Fig. 1). Indirect effects of open communication to depressive symptoms via self-concept clarity were tested using the model with stabilities, within-time T1 correlations, the T2- 


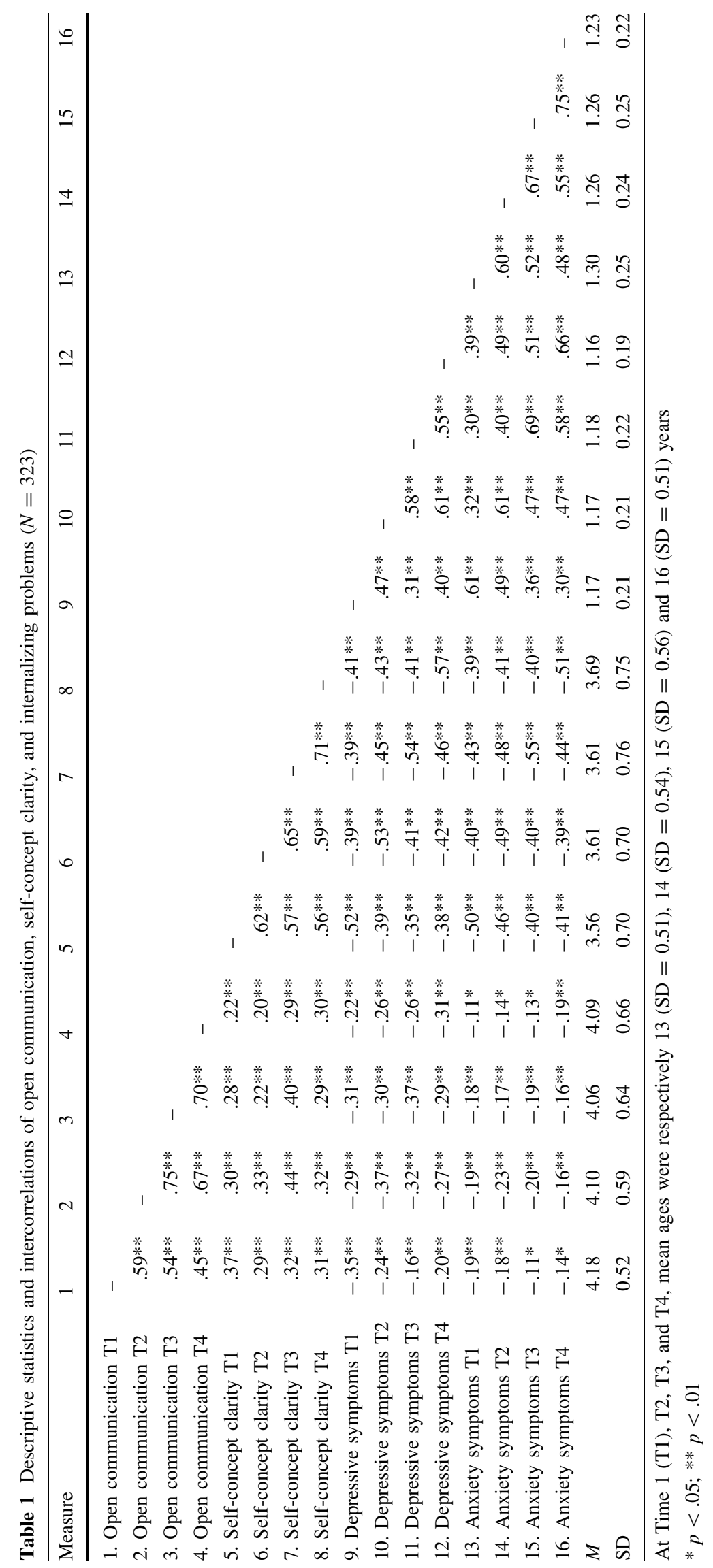


Table 2 Model fit comparisons of cross-lagged path analyses with open communication, self-concept clarity, and depressive or anxiety symptoms

\begin{tabular}{|c|c|c|c|c|c|c|c|c|}
\hline Model & $\chi^{2} \mathrm{SB}$ & $d f$ & CFI & RMSEA & Model comparison & $\Delta \chi^{2} \mathrm{SB}$ & $\Delta d f$ & $p$ \\
\hline \multicolumn{9}{|c|}{ Open communication, self-concept clarity, and depressive symptoms } \\
\hline 0: Baseline model & $74.889 * *$ & 36 & .968 & .058 & & & & \\
\hline 1: $0+$ Open communication $\rightarrow$ SCC & $54.760 *$ & 33 & .982 & .045 & 1 versus 0 & 21.461 & 3 & $<.001$ \\
\hline 2: $1+\mathrm{SCC} \rightarrow$ depressive symptoms & 30.021 & 30 & 1.000 & .001 & 2 versus 1 & 25.499 & 3 & $<.001$ \\
\hline 3: $2+$ Depressive symptoms $\rightarrow$ SCC & 28.179 & 27 & .999 & .012 & 3 versus 2 & 2.145 & 3 & .54 \\
\hline 4: $3+\mathrm{SCC} \rightarrow$ open communication & 22.653 & 24 & 1.000 & $<.001$ & 4 versus 3 & 5.625 & 3 & .13 \\
\hline \multicolumn{9}{|c|}{ Open communication, self-concept clarity, and anxiety } \\
\hline 0: Baseline model & $85.728 * *$ & 36 & .964 & .065 & & & & \\
\hline 1: $0+$ Open communication $\rightarrow$ SCC & $59.207 * *$ & 33 & .981 & .050 & 1 versus 0 & 29.934 & 3 & $<.001$ \\
\hline $2: 1+$ SCC $\rightarrow$ anxiety & 37.597 & 30 & .995 & .028 & 2 versus 1 & 23.006 & 3 & $<.001$ \\
\hline 3: $2+$ Anxiety $\rightarrow$ SCC & 22.669 & 27 & 1.000 & $<.001$ & 3 versus 2 & 16.426 & 3 & $<.001$ \\
\hline 4: $3+$ SCC $\rightarrow$ open communication & 16.835 & 24 & 1.000 & $<.001$ & 4 versus 3 & 5.795 & 3 & .12 \\
\hline
\end{tabular}

SCC self-concept clarity

$* p<.05 ; * * p<.01$

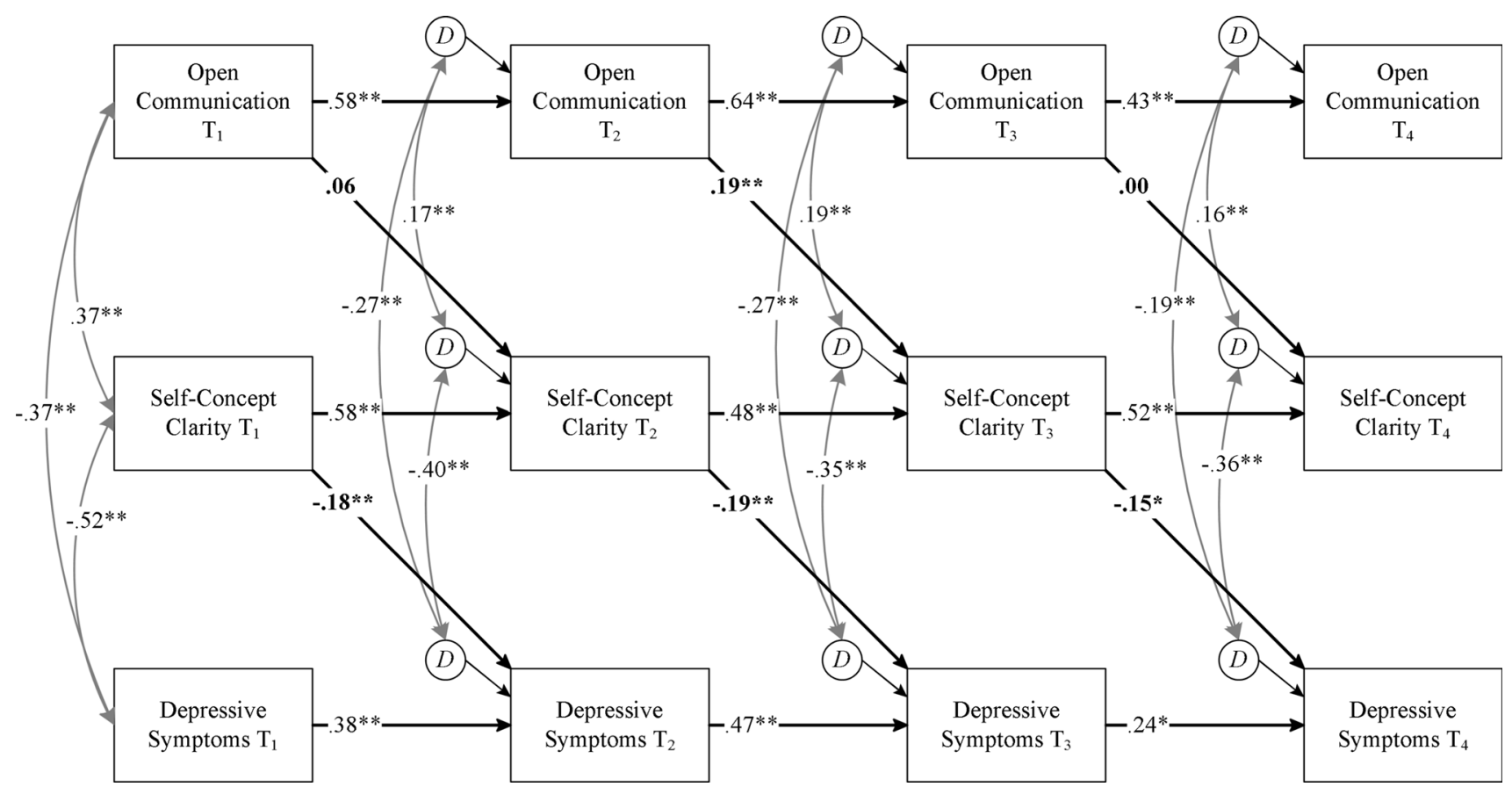

Fig. 2 Final cross-lagged panel model with self-concept clarity, open communication with parents, and depressive symptoms over time. Depicted are standardized coefficients of within-time correlations and correlated residuals (grey arrows), stabilities, and cross-lagged paths.
$D$ disturbance. At Time 1 (T1), T2, T3, and T4, mean ages were respectively $13(\mathrm{SD}=0.51), 14(\mathrm{SD}=0.54), 15(\mathrm{SD}=0.56)$ and 16 $(\mathrm{SD}=0.51)$ years. $* p<.05 ; * * p<.01$

self-concept clarity (T3) to later depressive symptoms (T4), the indirect effects were weak and nonsignificant $\left(\beta_{\mathrm{T} 1}\right.$ open communication $\rightarrow \mathrm{T} 2$ self-concept clarity $\rightarrow \mathrm{T} 3$ depressive symptoms $=-.01, p=.181,95 \% \mathrm{CI}-.030$ to $.006 ; \beta_{\mathrm{T} 2}$ open com-

munication $\rightarrow \mathrm{T} 3$ self-concept clarity $\rightarrow \mathrm{T} 4$ depressive symptoms $=-.03$,
T4 correlated residuals, and cross-lagged paths from open communication to self-concept clarity and from self-concept clarity to depressive symptoms. Despite the fact that we found significant effects both from open communication (T2) to later self-concept clarity (T3), and from 


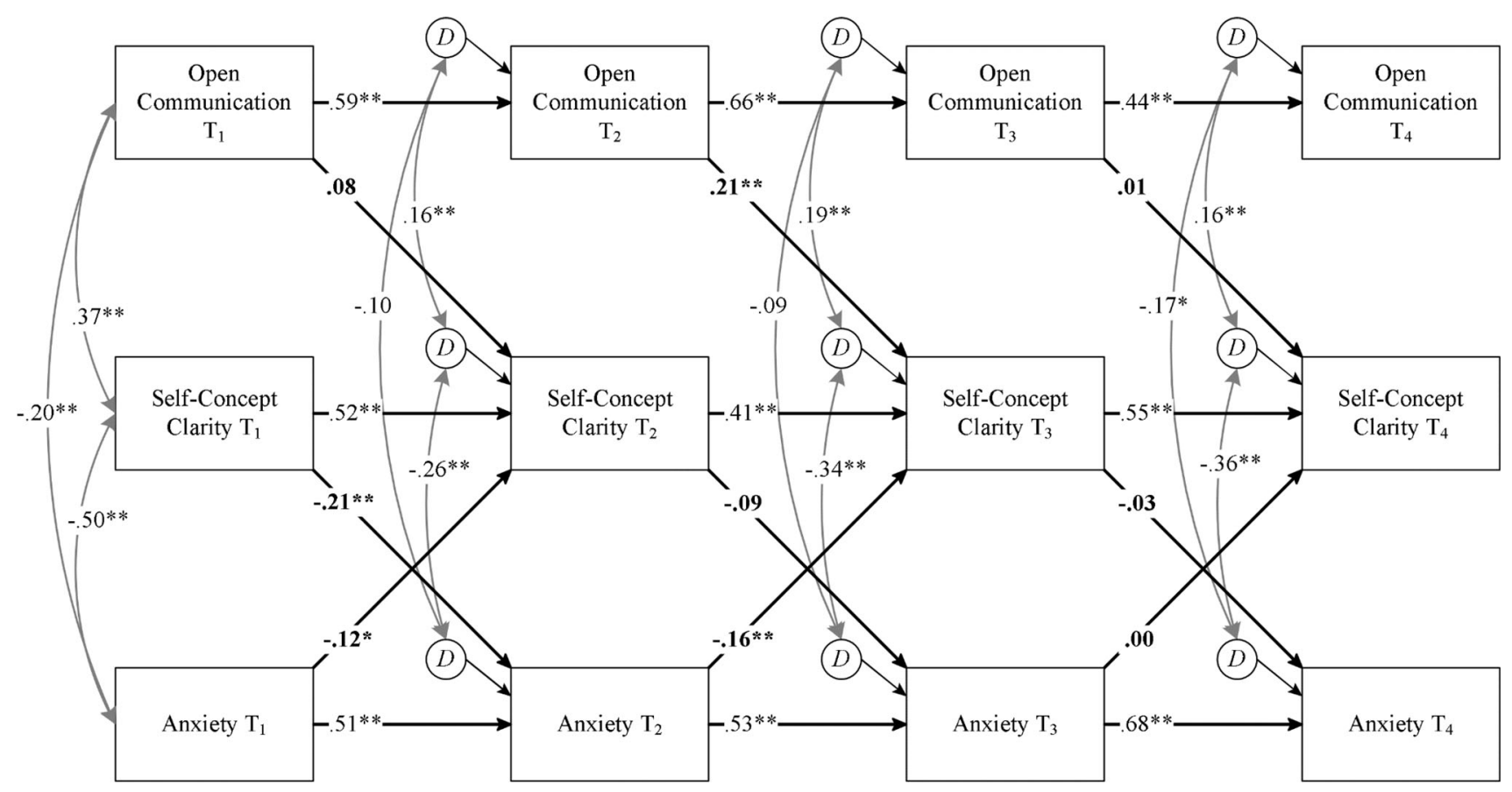

Fig. 3 Final cross-lagged panel model with self-concept clarity, open communication with parents, and anxiety over time. Depicted are standardized coefficients of within-time correlations and correlated residuals (grey arrows), stabilities, and cross-lagged paths.

$p=.069,95 \% \mathrm{CI}-.058$ to .002). Therefore, we found no support for a mediation effect of self-concept clarity in the association between open communication and depressive symptoms.

Indirect effects from open communication to anxiety symptoms via self-concept clarity were tested using the model with stabilities, within-time T1 correlations, the T2T4 correlated residuals, and cross-lagged paths from open communication to self-concept clarity, from anxiety symptoms to self-concept clarity and from self-concept clarity to anxiety symptoms (Fig. 1). As in the previous model, indirect effects were weak and nonsignificant $\left(\beta_{[\mathrm{T} 1}\right.$ open communication $\rightarrow \mathrm{T} 2$ self-concept clarity $\rightarrow \mathrm{T} 3$ anxiety symptoms] $=-.01, p=.166,95 \% \mathrm{CI}-.017$ to $.003 ; \beta_{[\mathrm{T} 2}$ open communication $\rightarrow \mathrm{T} 3$ self-concept clarity $\rightarrow \mathrm{T} 4$ anxiety symptoms] $=-.01$, $p=.555,95 \%$ CI -.028 to .015). Hence, also for the link between open communication and anxiety symptoms, selfconcept clarity did not act as a mediator in this study.

\section{Discussion}

In adolescence, clarifying one's self-concept is integral to the important task of developing one's identity (Bigler et al. 2001; Campbell et al. 1996; Erikson 1963; Schwartz et al. 2010). We hypothesized that open communication with parents would be linked to this process, because self-
$D$ disturbance. At Time 1 (T1), T2, T3, and T4, mean ages were respectively $13(\mathrm{SD}=0.51), 14(\mathrm{SD}=0.54), 15(\mathrm{SD}=0.56)$ and 16 $(\mathrm{SD}=0.51)$ years. $* p<.05 ; * * p<.01$

reflective thinking and talking within this communication enhances understanding of the self (Habermas and Bluck 2000). In an adaptive development, adolescents are able to integrate their need to construct a separate self and their need for warm relationships with their parents (Adams and Marshall 1996; Grotevant and Cooper 1985; Hill and Holmbeck 1986). We thought that self-concept clarity may also predict open communication, as understanding of oneself influences individuals' reactions and levels of disclosure to important others (Aron 2003). To our knowledge, no study has examined this possibility. Hence, we tested the bidirectional links between open communication with parents and self-concept clarity. We also hypothesized that depressive and anxiety symptoms would be linked to self-concept clarity, because adolescents' increased frequency of thinking about oneself and uncertainty about their self-concepts may relate to internalizing problems (Campbell et al. 2003; Habermas and Bluck 2000). Therefore, the goal of this 4-year study was to examine the concurrent and over-time associations between open communication with parents, self-concept clarity, and internalizing problems (i.e., depressive and anxiety symptoms) in adolescence. To our knowledge, this study is the first to link prior investigations of open adolescent-parent communication and self-concept clarity with past research on self-concept clarity and internalizing symptoms. 
Table 3 Coefficients of the final cross-lagged path models with open communication, self-concept clarity, and depressive or anxiety symptoms

\begin{tabular}{|c|c|c|c|c|c|c|c|c|}
\hline & $\mathrm{T}$ & $\begin{aligned} & 95 \% \mathrm{CI} \\
\rightarrow & \mathrm{T} 2\end{aligned}$ & $\mathrm{~T}$ & $\begin{aligned} & 95 \% \mathrm{CI} \\
\rightarrow & \mathrm{T} 3\end{aligned}$ & $\beta$ & $\begin{aligned} & 95 \% \mathrm{CI} \\
\rightarrow & \mathrm{T} 4\end{aligned}$ & $\beta$ & $95 \% \mathrm{CI}$ \\
\hline \multicolumn{9}{|l|}{ OC, SCC, depr. symptoms } \\
\hline \multicolumn{9}{|l|}{ Stability paths } \\
\hline $\mathrm{OC}$ & $.582 * *$ & $.502, .661$ & $.637 * *$ & $.547, .728$ & $.432 * *$ & $.306, .558$ & & \\
\hline SCC & $.577 * *$ & $.495, .660$ & $.483 * *$ & $.386, .581$ & $.522 * *$ & $.405, .639$ & & \\
\hline Depr. symptoms & $.375^{* *}$ & $.207, .544$ & $.465 * *$ & $.320, .610$ & $.239 *$ & $.043, .434$ & & \\
\hline \multicolumn{9}{|l|}{ Cross-lagged effects } \\
\hline $\mathrm{OC} \rightarrow \mathrm{SCC}$ & .064 & $-.025, .154$ & $.191 * *$ & $.119, .263$ & .001 & $-.093, .095$ & & \\
\hline \multirow[t]{2}{*}{ SCC $\rightarrow$ depr. symptoms } & $-.181 * *$ & $-.300,-.062$ & $-.191 * *$ & $-.293,-.088$ & $-.145^{*}$ & $-.283,-.006$ & & \\
\hline & \multicolumn{2}{|r|}{$\mathrm{T} 1$} & \multicolumn{2}{|r|}{$\mathrm{T} 2$} & \multicolumn{2}{|r|}{$\mathrm{T} 3$} & \multicolumn{2}{|r|}{$\mathrm{T} 4$} \\
\hline \multicolumn{9}{|c|}{ Correlations/correlated residuals } \\
\hline $\mathrm{OC}-\mathrm{SCC}$ & $.375^{* *}$ & $.283, .467$ & $.170 * *$ & $.061, .279$ & $.189 * *$ & $.055, .324$ & $.158 * *$ & $.045, .272$ \\
\hline SCC-depr. symptoms & $-.522 * *$ & $-.605,-.438$ & $-.397 * *$ & $-.498,-.297$ & $-.347 * *$ & $-.498,-.195$ & $-.357 * *$ & $-.491,-.223$ \\
\hline \multirow[t]{2}{*}{ OC-depr. symptoms } & $-.371 * *$ & $-.484,-258$ & $-.270 * *$ & $-.414,-.126$ & $-.266^{* *}$ & $-.386,-.146$ & $-.191 * *$ & $-.304,-.078$ \\
\hline & \multicolumn{2}{|c|}{$\mathrm{T} 1 \rightarrow \mathrm{T} 2$} & \multicolumn{2}{|c|}{$\mathrm{T} 2 \rightarrow \mathrm{T} 3$} & \multicolumn{2}{|c|}{$\mathrm{T} 3 \rightarrow \mathrm{T} 4$} & & \\
\hline
\end{tabular}

OC, SCC, anxiety

Stability paths

\begin{tabular}{|c|c|c|c|c|c|c|c|c|}
\hline $\mathrm{OC}$ & $.589 * *$ & $.507, .670$ & $.661 * *$ & $.574, .748$ & $.443 * *$ & $.320, .567$ & & \\
\hline SCC & $.517 * *$ & $.417, .616$ & $.412 * *$ & $.308, .517$ & $.550 * *$ & $.425, .675$ & & \\
\hline Anxiety & $.505^{* *}$ & $.359, .650$ & $.533 * *$ & $.324, .743$ & $.679 * *$ & $.529, .829$ & & \\
\hline \multicolumn{9}{|l|}{ Cross-lagged effects } \\
\hline $\mathrm{OC} \rightarrow \mathrm{SCC}$ & .080 & $-.012, .171$ & $.207 * *$ & $.142, .272$ & .005 & $-.089,099$ & & \\
\hline SCC $\rightarrow$ anxiety & $-.206 * *$ & $-.311,-.100$ & -.088 & $-.183, .007$ & -.031 & $-.133,071$ & & \\
\hline \multirow[t]{2}{*}{ Anxiety $\rightarrow$ SCC } & $-.119 *$ & $-.225,-.014$ & $-.158 * *$ & $-.242,-.075$ & .004 & $-.087, .095$ & & \\
\hline & & $\mathrm{T} 1$ & & $\mathrm{~T} 2$ & & $\mathrm{~T} 3$ & & $\mathrm{~T} 4$ \\
\hline \multicolumn{9}{|c|}{ Correlations/correlated residuals } \\
\hline $\mathrm{OC}-\mathrm{SCC}$ & $.372 * *$ & $.218, .464$ & $.162 * *$ & $.052, .273$ & $.190 * *$ & $.058, .322$ & $.157 * *$ & $.043, .271$ \\
\hline SCC-anxiety & $-.495 * *$ & $-.582,-.407$ & $-.256 * *$ & $-.366,-.147$ & $-.336 * *$ & $-.468,-.204$ & $-.357 * *$ & $-.478,-.236$ \\
\hline OC-anxiety & $-.199 * *$ & $-.314,-.083$ & -.104 & $-.240, .031$ & -.090 & $-.203, .023$ & $-.171 *$ & $-.304,-.037$ \\
\hline
\end{tabular}

At Time $1(\mathrm{~T} 1), \mathrm{T} 2, \mathrm{~T} 3$, and T4, mean ages were respectively $13(\mathrm{SD}=0.51), 14(\mathrm{SD}=0.54), 15(\mathrm{SD}=0.56)$ and $16(\mathrm{SD}=0.51)$ years. Twoand three-year stability paths were included in the model but are not displayed

$C I$ confidence interval, $O C$ open communication with parents, SCC self-concept clarity, depr. symptoms depressive symptoms

$* p<.05 ; * * p<.01$

\section{Links Between Open Communication and Self-Concept Clarity}

In accordance with our hypothesis, higher open communication with parents showed consistent, small-sized withintime links and correlated residuals with higher self-concept clarity. Open communication preceded higher self-concept clarity only in middle adolescence (from T2 to T3). We found no longitudinal associations from self-concept clarity to open communication. The finding that higher open communication preceded higher self-concept clarity (although not consistently over time) matches the theoretical rationale that talking about the self and one's life is important in the development of the self, and enhances selfunderstanding by forming links between elements of one's life and the self (Grotevant 2001; Habermas and Bluck 2000; McLean et al. 2007). The finding also fits the idea that open communication between adolescents and parents, in which parents are supportive of the adolescent's viewpoints and are active listeners, promotes positive development and 
self-understanding (McLean et al. 2007). Our finding extends results of previous studies among adolescents that have found positive cross-sectional links between open communication with parents and identity exploration (Meeus et al. 2002), and positive links between open communication with parents (i.e., less secrets) and self-concept clarity 6 months later (Frijns and Finkenauer 2009). Although we found that open communication with parents preceded higher self-concept clarity, a substantive effect was only found from open communication at Time 2 (mean age 14 years) to self-concept clarity at Time 3 (mean age 15 years). It is unclear why exactly only an effect at these waves existed, despite the fact that the instruments had an adequate reliability at all measurements. It may be that the role of parents in the development of self-concept clarity is most important in early to middle adolescence, as parents' influence decreases and the influence from friends increases during adolescence (De Goede et al. 2009; Frijns et al. 2010). Future studies are needed to replicate these findings.

\section{Links Between Self-Concept Clarity and Internalizing Problems}

As expected, adolescents who reported lower self-concept clarity also reported more depressive and anxiety symptoms, and lower self-concept clarity predicted higher internalizing problems over time. We found longitudinal effects from lower self-concept clarity to higher levels of depressive symptoms at all waves, but lower self-concept clarity predicted higher anxiety only at earlier ages. Perhaps this effect only existed at these younger ages because anxiety symptoms appear to become more stable between ages 12 and 16 (Schwartz et al. 2012). The finding that lower self-concept clarity preceded higher levels of internalizing problems corresponds to the idea that periods of heightened self-reflection in the development of self-concept clarity go together with youths' struggles over problematic issues, which can lead or contribute to temporary declines in self-esteem and higher levels of internalizing problems (Bell et al. 2004; Campbell et al. 2003; Habermas and Bluck 2000; Panayiotou and Kokkinos 2006). Our findings extend the results of previous studies that found negative longitudinal associations between self-concept clarity or confusion regarding identity processes and later internalizing problems (Lee-Flynn et al. 2011; Schwartz et al. 2010). In sum, our results are in accordance with the bidirectional links between self-concept clarity and depressive and anxiety symptoms reported by Schwartz et al. (2012), but our more rigorous test of age differences in these links revealed that self-concept clarity predicts later anxiety symptoms only in early adolescence (T1-T2).

Although we could think of depression as a risk factor for difficulties in developing the self, no relations were found between depressive symptoms and later self-concept clarity. In contrast, more anxiety symptoms did precede lower self-concept clarity over time. Longitudinal effects were found for anxiety symptoms at Time 1 to self-concept clarity at Time 2 , and for anxiety at Time 2 to self-concept clarity at Time 3 (mean age 15 years). These findings are in line with another study indicating that high anxiety is considered a risk factor for problematic identity development (Crocetti et al. 2009). Adolescents higher in anxiety exhibit less identity exploration and have more uncertainty regarding commitments, matching our finding that higher anxiety levels preceded lower self-concept clarity. Perhaps anxiety is less related to exploration in late adolescence, and therefore no effect of anxiety symptoms to self-concept clarity could be found from Time 3 to Time 4 . Our results also underscore the importance of distinguishing between depressive symptoms and anxiety symptoms. In contrast to Schwartz et al. (2012), who used a larger sample and constrained age effects to be similar across ages, we found no effect from depressive symptoms to later self-concept clarity, and an effect of anxiety symptoms on self-concept clarity was present only in early to middle adolescence. Future studies using broader age ranges are needed to clarify these contradicting findings. In conclusion, we found that lower self-concept clarity preceded higher levels of depressive symptoms across all waves, as well as higher levels of anxiety symptoms in earlier adolescence, while higher levels of anxiety symptoms preceded lower selfconcept clarity only in early to middle adolescence.

\section{Self-Concept Clarity as a Mediator?}

Finally, in contrast to our hypothesis, we did not find longitudinal mediation effects of self-concept clarity in the associations between open communication and internalizing symptoms. Several studies have reported a link between adolescents' communication with parents and aspects of psychosocial well-being, including depressive symptoms, all suggesting that open communication may protect against depressive symptoms (e.g., Frijns and Finkenauer 2009; Frijns et al. 2010; Jackson et al. 1998; Kerr and Stattin 2000). The mechanisms underlying this link remain unclear, and the current study tested one of the possible underlying processes. The current research demonstrated consistent medium-sized within-time links and correlated residuals between open communication with parents and depressive symptoms, which suggests overlapping developmental changes. Interestingly, these concurrent associations were stronger and more consistent for open communication and depressive symptoms than for open communication and anxiety symptoms. However, none of the mediation effects that we tested were significant. It could be that mediation takes place within a smaller 
time period, and shorter time intervals of measurement are needed to examine this possibility. Alternatively, it could be that the association between open communication with parents and internalizing problems is instead mediated by other factors. For example, a lack of open communication could indicate less warmth and support in the parent-child relationship (Kerr et al. 1999; Tilton-Weaver and Marshall 2008), or may even precede parental withdrawal from the relationship (Finkenauer et al. 2005). Such factors are also known to predict later internalizing problems in adolescence (Branje et al. 2010; Brenning et al. 2012; Hair et al. 2008; Van Eijck et al. 2012).

\section{Strengths, Limitations, and Future Studies}

The strengths of this study include the use of a longitudinal design with a large sample. Furthermore, our cross-lagged panel design controlled for concurrent associations at T1, correlated residuals at $\mathrm{T} 2-\mathrm{T} 4$, and stability over time. In this way, the research helped to illuminate the over-time associations of different, co-developing constructs. There are also limitations. First, the data were gathered with selfreport questionnaires, and including other reporters might increase the validity of our findings. In addition, questions regarding open communication concerned the communication with both parents together, while adolescents' communication with their mothers and fathers can differ (Keijsers et al. 2010; Waizenhofer et al. 2004). Thus, it could be better to ask adolescents to report on their communication with fathers and mothers, separately, which would inform the generalizability of the process across parents. Besides this possible difference between fathers and mothers, future studies could examine whether there is an interaction effect between adolescent gender and parent gender. For example, one study showed that girls' communication with both fathers and mothers was related to identity exploration, while only boys' communication with their fathers was associated with identity exploration (Grotevant and Cooper 1985). Finally, adolescents came from relatively well-functioning families, which limits the generalizability of our findings, especially when it comes to the clinical range of problem behaviors. Symptoms were also assessed instead of DSM diagnoses.

Future studies can contribute to a better understanding of how self-concept clarity emerges, and what the consequences of low self-concept clarity might be. First, it would be interesting to examine whether open communication with friends also predicts self-concept clarity, as constructing narratives in multiple relationships may be important to the development of the self (Grotevant 2001; Habermas and Bluck 2000; McLean et al. 2007), and communication with friends becomes increasingly important in adolescence (Frijns et al. 2010; Youniss and Smollar
1985). Furthermore, adding a measure of thinking about oneself, in addition to a measure of talking about oneself (open communication), can further clarify the links between open communication and self-concept clarity, and between self-concept clarity and internalizing problems. In the same realm, a measure of rumination (Campbell et al. 1996) would be interesting because adolescents may ruminate in the development of a clear self-concept, which is a strong predictor of internalizing problems (Panayiotou and Kokkinos 2006). Finally, extending the examined period into young adulthood could contribute to the knowledge gleaned from the present study, as development of the self and identity continues beyond adolescence (Arnett 2000; Valde 1996).

\section{Conclusion}

Our 4-year study showed that open communication with parents and self-concept clarity are concurrently related to each other, as are self-concept clarity and depressive and anxiety symptoms, respectively. In middle adolescence (T2-T3), higher levels of open communication with parents preceded higher self-concept clarity. An important finding is that lower self-concept clarity predicted higher levels of depressive symptoms across all waves. Less consistently, lower self-concept clarity preceded higher levels of anxiety only from T1 to T2 (mean ages 13 and 14). Higher anxiety was followed by lower self-concept clarity in early to middle adolescence. In conclusion, the findings suggest that a less clear self-concept precedes higher levels of depressive symptoms across adolescence and, although less consistently, higher levels of anxiety symptoms. Furthermore, this study highlights the potential importance of both anxiety symptoms and communication with parents in the development of a clear self-concept. Although more research is needed, this study adds to the understanding of positive influences on adolescents' development. For adolescents who are unsure of who they are, and who have an unstable self-concept that is easily influenced by their environment, intervention may be needed in order to prevent or minimize internalizing problems. According to our findings, adolescent-parent communication processes could be a focus for prevention or intervention efforts. To stimulate both cohesion and individuality, parents and their adolescents might benefit from more information about how they can improve their communication. Because open communication with parents, clarity of the self-concept, and depressive and anxiety symptoms seem to be closely interrelated over time, open communication with parents and developing a clearer selfconcept might be two essential focus areas for decreasing or preventing further problematic development. 
Acknowledgments This study was supported by grants to Wim Meeus and Susan Branje from the Netherlands Organization for Scientific Research (NWO).

Author contributions M.P.A.D. conceived of the study, performed the statistical analyses, interpreted the results, and wrote the manuscript. S.B. participated in the conceiving of the study, the data analysis, the interpretation of the results and the drafting of the manuscript. L.K. helped with the statistical analyses and participated in the interpretation of the results and in the drafting of the manuscript. W.M. participated in the interpretation of the results and revised the manuscript. W.M. is also the principal investigator of the CONAMORE project and is responsible for the data collection. S.T.H. participated in the drafting of the manuscript, and S.T.H. and W.W.H. revised the manuscript. All authors read and approved the final manuscript.

\section{References}

Adams, G. R., \& Marshall, S. K. (1996). A developmental social psychology of identity: Understanding the person-in-context. Journal of Adolescence, 19, 429-442.

Arnett, J. J. (1999). Adolescent storm and stress, reconsidered. American Psychologist, 54, 317-326.

Arnett, J. J. (2000). Emerging adulthood: A theory of development from the late teens through the twenties. American Psychologist, $55,469-480$.

Aron, A. (2003). Self and close relationships. In M. R. Leary \& J. P. Tangney (Eds.), Handbook of self and identity (pp. 442-461). New York, NY: Guilford Press.

Barnes, H. L., \& Olson, D. H. (1985). Parent-adolescent communication and the circumplex model. Child Development, 56, 438-447.

Bell, R. Q. (1968). A reinterpretation of the direction of effects in studies of socialization. Psychological Review, 75, 81-95.

Bell, N. J., Wieling, E., \& Watson, W. (2004). Self-reflecting in developmental context: Variations in level and patterning during the first 2 university years. The Journal of Genetic Psychology, 165, 451-465.

Bigler, M., Neimeyer, G. J., \& Brown, E. (2001). The divided self revisited: Effects of self-concept clarity and self-concept differentiation on psychological adjustment. Journal of Social and Clinical Psychology, 20, 396-415.

Birmaher, B., Brent, D. A., Chiappetta, L., Bridge, J., Monga, S., \& Baugher, M. (1999). Psychometric properties of the Screen for Child Anxiety Related Emotional Disorders Scale (SCARED): A replication study. Journal of the American Academy of Child and Adolescent Psychiatry, 38, 1230-1236.

Birmaher, B., Khetarpal, S., Brent, D., Cully, M., Balach, L., Kaufman, J., et al. (1997). The Screen for Child Anxiety Related Emotional Disorders (SCARED): Scale construction and psychometric characteristics. Journal of the American Academy of Child and Adolescent Psychiatry, 36, 545-553.

Bollen, K. A. (1989). Structural equations with latent variables. New York, NY: Wiley.

Branje, S. J. T., Hale, W. W., III, Frijns, T., \& Meeus, W. H. J. (2010). Longitudinal associations between perceived parentchild relationship quality and depressive symptoms in adolescence. Journal of Abnormal Child Psychology, 38, 751-763.

Brenning, K., Soenens, B., Braet, C., \& Bal, S. (2012). The role of parenting and mother-adolescent attachment in the intergenerational similarity of internalizing symptoms. Journal of Youth and Adolescence, 41, 802-816.
Burt, K. B., \& Roisman, G. I. (2010). Competence and psychopathology: Cascade effects in the NICHD study of early child care and youth development. Development and Psychopathology, 22, 557-567.

Campbell, J. D. (1990). Self-esteem and clarity of the self-concept. Journal of Personality and Social Psychology, 59, 538-549.

Campbell, J. D., Assanand, S., \& Di Paula, A. (2003). The structure of the self-concept and its relation to psychological adjustment. Journal of Personality, 71, 115-140.

Campbell, J. D., Trapnell, P. D., Heine, S. J., Katz, I. M., Lavallee, L. F., \& Lehman, D. R. (1996). Self-concept clarity: Measurement, personality correlates, and cultural boundaries. Journal of Personality and Social Psychology, 70, 141-156.

Cohen, J. (1988). Statistical power analysis for the behavioral sciences. Hillsdale, NJ: Lawrence Erlbaum.

Craighead, W. E., Smucker, M. R., Craighead, L. W., \& Ilardi, S. S. (1998). Factor analysis of the children's depression inventory in a community sample. Psychological Assessment, 10, 156-165.

Crocetti, E., Klimstra, T., Keijsers, L., Hale, W. W., III, \& Meeus, W. (2009). Anxiety trajectories and identity development in adolescence: A five-wave longitudinal study. Journal of Youth and Adolescence, 38, 839-849.

De Goede, I. H. A., Branje, S. J. T., Delsing, M. J. M. H., \& Meeus, W. H. J. (2009). Linkages over time between adolescents' relationships with parents and friends. Journal of Youth and Adolescence, 38, 1304-1315.

Donahue, E. M., Robins, R. W., Roberts, B. W., \& John, O. P. (1993). The divided self: Concurrent and longitudinal effects of psychological adjustment and social roles on self-concept differentiation. Journal of Personality and Social Psychology, 64, 834-846.

Enders, C. K., \& Bandalos, D. L. (2001). The relative performance of full information maximum likelihood estimation for missing data in structural equation models. Structural Equation Modeling, 8, 430-457.

Erikson, E. H. (1963). Childhood and society (2nd ed.). New York, NY: Norton.

Finkenauer, C., Engels, R. C. M. E., \& Meeus, W. (2002). Keeping secrets from parents: Advantages and disadvantages of secrecy in adolescence. Journal of Youth and Adolescence, 31, 123-136.

Finkenauer, C., Frijns, T., Engels, R. C. M. E., \& Kerkhof, P. (2005). Perceiving concealment in relationships between parents and adolescents: Links with parental behavior. Personal Relationships, 12, 387-406.

Frijns, T., \& Finkenauer, C. (2009). Longitudinal associations between keeping a secret and psychosocial adjustment in adolescence. International Journal of Behavioral Development, $33,145-154$.

Frijns, T., Keijsers, L., Branje, S., \& Meeus, W. (2010). What parents don't know and how it may affect their children: Qualifying the disclosure-adjustment link. Journal of Adolescence, 33, 261-270.

Grotevant, H. D. (2001). Developing new insights from a process approach to adolescent development. Human Development, 44, $55-58$.

Grotevant, H. D., \& Cooper, C. R. (1985). Patterns of interaction in family relationships and the development of identity exploration in adolescence. Child Development, 56, 415-428.

Habermas, T., \& Bluck, S. (2000). Getting a life: The emergence of the life story in adolescence. Psychological Bulletin, 126, 748-769.

Hair, E. C., Moore, K. A., Garrett, S. B., Ling, T., \& Cleveland, K. (2008). The continued importance of quality parent-adolescent relationships during late adolescence. Journal of Research on Adolescence, 18, 187-200.

Hale, W. W., III, Crocetti, E., Raaijmakers, Q. A. W., \& Meeus, W. H. J. (2011). A meta-analysis of the cross-cultural 
psychometric properties of the Screen for Child Anxiety Related Emotional Disorders (SCARED). Journal of Child Psychology and Psychiatry, 52, 80-90.

Hill, J. P., \& Holmbeck, G. N. (1986). Attachment and autonomy during adolescence. Annals of Child Development, 3, 145-189.

Hu, L., \& Bentler, P. M. (1999). Cut-off criteria for fit indexes in covariance structure analysis: Conventional criteria versus new alternatives. Structural Equation Modeling, 6, 1-55.

Jackson, S., Bijstra, J., Oostra, L., \& Bosma, H. (1998). Adolescents' perceptions of communication with parents relative to specific aspects of relationships with parents and personal development. Journal of Adolescence, 21, 305-322.

Jung, E. (2013). Delineation of a threefold relationship among communication input variables, identity gaps, and depressive symptoms. Southern Communication Journal, 78, 163-184.

Keijsers, L., Branje, S. J. T., Van der Valk, I. E., \& Meeus, W. (2010). Reciprocal effects between parental solicitation, parental control, adolescent disclosure, and adolescent delinquency. Journal of Research on Adolescence, 20, 88-113.

Kerr, M., \& Stattin, H. (2000). What parents know, how they know it, and several forms of adolescent adjustment: Further support for a reinterpretation of monitoring. Developmental Psychology, 36, 366-380.

Kerr, M., \& Stattin, H. (2003). Parenting of adolescents: Action or reaction? In A. Booth \& A. C. Crouter (Eds.), Children's influence on family dynamics: The neglected side of family relationships (pp. 121-151). Mahwah, NJ: Lawrence Erlbaum Associates.

Kerr, M., Stattin, H., \& Trost, K. (1999). To know you is to trust you: Parents' trust is rooted in child disclosure of information. Journal of Adolescence, 22, 737-752.

Kline, R. B. (2011). Principles and practice of structural equation modeling (3rd ed.). New York, NY: Guilford Press.

Lee-Flynn, S. C., Pomaki, G., DeLongis, A., Biesanz, J. C., \& Puterman, E. (2011). Daily cognitive appraisals, daily affect, and long-term depressive symptoms: The role of self-esteem and self-concept clarity in the stress process. Personality and Social Psychology Bulletin, 37, 255-268.

Little, R. J. A. (1988). A test of missing completely at random for multivariate data with missing values. Journal of the American Statistical Association, 83, 1198-1202.

Marcia, J. E. (1966). Development and validation of ego-identity status. Journal of Personality and Social Psychology, 3, $551-558$

McLean, K. C., Pasupathi, M., \& Pals, J. L. (2007). Selves creating stories creating selves: A process model of self-development. Personality and Social Psychology Review, 11, 262-278.

Meeus, W. H. J., Akse, J., Branje, S. J. T., Ter Bogt, T. F. M., Crommelin, P. M., Delsing, M. J., et al. (2006). Codebook of the research project conflict and management of relationships (CONAMORE). Unpublished manuscript. Utrecht, The Netherlands: Utrecht University.

Meeus, W., Iedema, J., Maassen, G., \& Engels, R. (2005). Separationindividuation revisited: On the interplay of parent-adolescent relations, identity and emotional adjustment in adolescence. Journal of Adolescence, 28, 89-106.

Meeus, W., Oosterwegel, A., \& Vollebergh, W. (2002). Parental and peer attachment and identity development in adolescence. Journal of Adolescence, 25, 93-106.

Meeus, W., Van de Schoot, R., Keijsers, L., Schwartz, S. J., \& Branje, S. (2010). On the progression and stability of adolescent identity formation. A five-wave longitudinal study in early-to-middle and middle-to-late adolescence. Child Development, 81, 1565-1581.

Muthén, L. K., \& Muthén, B. O. (1998-2012). Mplus user's guide (7th ed.). Los Angeles, CA: Muthén \& Muthén.
Nezlek, J. B., \& Plesko, R. M. (2001). Day-to-day relationships among self-concept clarity, self-esteem, daily events, and mood. Personality and Social Psychology Bulletin, 27, 201-211.

Panayiotou, G., \& Kokkinos, C. M. (2006). Self-consciousness and psychological distress: A study using the Greek SCS. Personality and Individual Differences, 41, 83-93.

Pearsall Smith, L. (1931). Age and Death. Afterthoughts. London, England: Constable.

Satorra, A., \& Bentler, P. M. (1994). Corrections to test statistics and standard errors in covariance structure analysis. In A. von Eye \& C. C. Clogg (Eds.), Latent variables analysis: Applications for developmental research (pp. 399-419). Thousand Oaks, CA: Sage.

Satorra, A., \& Bentler, P. M. (2001). A scaled difference Chi square test statistic for moment-structure analysis. Psychometrika, 66, 507-514.

Schwartz, S. J., Klimstra, T. A., Luyckx, K., Hale, W. W., III, Frijns, T., Oosterwegel, A., et al. (2010). Daily dynamics of personal identity and self-concept clarity. European Journal of Personality, 25, 373-385.

Schwartz, S. J., Klimstra, T. A., Luyckx, K., Hale, W. W., III, \& Meeus, W. H. J. (2012). Characterizing the self-system over time in adolescence: Internal structure and associations with internalizing symptoms. Journal of Youth and Adolescence, 41, 1226-1239.

Shaw, C. L. M. (1997). Personal narrative: Revealing self and reflecting other. Human Communication Research, 24, 302-319.

Sowislo, J. F., \& Orth, U. (2013). Does low self-esteem predict depression and anxiety? A meta-analysis of longitudinal studies. Psychological Bulletin, 139, 213-240.

Tilton-Weaver, L., \& Marshall, S. (2008). Adolescents' agency in information management. In M. Kerr, H. Stattin, \& R. C. M. E. Engels (Eds.), What can parents do? New insights into the role of parents in adolescent problem behavior. Chichester, West Sussex, England: Wiley.

Valde, G. A. (1996). Identity closure: A fifth identity status. Journal of Genetic Psychology, 157, 245-254.

Van Doorn, M. D., Branje, S. J., \& Meeus, W. H. (2007). Longitudinal transmission of conflict resolution styles from marital relationships to adolescent-parent relationships. Journal of Family Psychology, 21, 426-434.

Van Eijck, F. E. A. M., Branje, S. J. T., Hale, W. W., III, \& Meeus, W. H. J. (2012). Longitudinal associations between perceived parent-adolescent attachment relationship quality and generalized anxiety disorder symptoms in adolescence. Journal of Abnormal Child Psychology, 40, 871-883.

Waizenhofer, R. N., Buchanan, C. M., \& Jackson-Newsom, J. (2004). Mothers' and fathers' knowledge of adolescents' daily activities: Its sources and its links with adolescent adjustment. Journal of Family Psychology, 18, 348-360.

Widaman, K. F. (2006). III. Missing data: What to do with or without them. Monographs of the Society for Research in Child Development, 71, 42-64.

Youniss, J., \& Smollar, J. (1985). Adolescent relations with mothers, fathers, and friends. Chicago, IL: University of Chicago Press.

\section{Author Biographies}

Marloes P. A. Van Dijk is a doctoral candidate at the Research Centre Adolescent Development of Utrecht University, The Netherlands. Her research interests include mental health, family processes, the influence of life events, and personality and identity development in adolescence and young adulthood. 
Susan Branje is Professor of Adolescent Development and Chair of the Research Centre Adolescent Development of Utrecht University. Her research interests include development of personality, psychosocial adjustment, and relationships with parents and friends in adolescence.

Loes Keijsers is an Assistant Professor at the Research Centre Adolescent Development at Utrecht University. Her research interests include parent-adolescent communication and secrecy, and delinquency.

Skyler T. Hawk works as a post-doctoral scholar at the Research Centre for Adolescent Development, Utrecht University. His research focuses on empathy and conflict resolution in families, as well as experiences of parental privacy invasion in adolescence.
William W. Hale III is an Associate Professor at the Research Centre on Adolescent Development, Utrecht University. His major research interests include adolescent depression and anxiety, and the effects parental interactions have on these psychosocial problem behaviors.

Wim Meeus is Professor of Adolescent Development at the Research Centre Adolescent Development at Utrecht University and Tilburg University. His research interests include identity, personality and relationships in adolescence. 